\title{
Recurrent laryngeal nerve injury following reoperative anterior cervical discectomy and fusion: a meta-analysis
}

\author{
Matthew S. Erwood, MD, ${ }^{1}$ Mark N. Hadley, MD, ${ }^{1}$ Amber S. Gordon, MD, ${ }^{1}$ William R. Carroll, MD, ${ }^{2}$ \\ Bonita S. Agee, PhD, ${ }^{1}$ and Beverly C. Walters, MD, MSc, FRCSC ${ }^{1}$ \\ Departments of ${ }^{1}$ Neurosurgery and ${ }^{2}$ Surgery, Division of Otolaryngology, University of Alabama at Birmingham, Alabama
}

OBJECTIVE Recurrent laryngeal nerve (RLN) injury is one of the most frequent complications of anterior cervical discectomy and fusion (ACDF) procedures. The frequency of RLN is reported as $1 \%-11 \%$ in the literature. 4,15 The rate of palsy after reoperative ACDF surgery is not well defined. This meta-analysis was performed to review the current medical evidence on RLN injury after ACDF surgery and to determine a relative rate of RLN injury after reoperative ACDF.

METHODS MEDLINE, PubMed, and Google Scholar searches were performed using several key words and phrases related to ACDF surgery. Included studies were written in English, addressed revisionary ACDF surgery, and studied outcomes of RLN injury. Statistical analysis was then performed using a random-effects model to calculate a pooled rate of RLN injury. The heterogeneity of the studies was assessed using Cochran's $Q$ statistic and $I^{2}$ statistic, and a funnel plot was constructed to evaluate publication bias.

RESULTS The search initially identified 345 articles on this topic. Eight clinical articles that met all inclusion criteria were included in the meta-analysis. A total of 238 patients were found to have undergone reoperative ACDF. Thirty-three of those patients experienced an RLN injury. This analysis identified a rate of RLN injury in the literature after reoperative ACDF of $14.1 \%$ (95\% confidence interval [Cl] 9.8\%-19.1\%).

CONCLUSIONS The rate of RLN palsy of $14.1 \%$ was greater than any published rate of RLN injury after primary ACDF operations, suggesting that there is a greater risk of hoarseness and dysphagia with reoperative ACDF surgeries than with primary procedures as reported in these studies.

http://thejns.org/doi/abs/10.3171/2015.9.SPINE15187

KEY WORDS reoperative ACDF surgery; recurrent laryngeal nerve palsy; anterior cervical discectomy and fusion

$\mathrm{R}$ ECURRENT laryngeal nerve (RLN) injury is the most recognized neurological complication associated with anterior cervical discectomy and fusion (ACDF). ${ }^{13}$ The frequency of RLN injury after ACDF surgery has been reported to be between $1 \%$ and $11 \% \%^{4,6,15,16}$ and is usually temporary. Permanent injury has been reported to occur $1 \%-5 \%$ of the time. Injury to this nerve can occur via direct intraoperative sectioning, but more commonly, by indirect compression or tension. Mechanisms for indirect injury have been described, and include stretching as a result of retraction, compression through inflation of the endotracheal cuff, and from airway trauma during intubation. ${ }^{2}$

Very little data are available, however, on the frequency of RLN injury after revision ACDF surgery. It has been proposed that anatomical differences from scarring after previous ACDF lead to greater rates of RLN injury during reoperative ACDF surgery. However, evidence in the literature of this notion is lacking. The goal of our study was to perform a meta-analysis on RLN injury after revision ACDF surgery. We hypothesized that the rate of RLN injury is greater with revision ACDF surgery compared with initial ACDF surgery.

\section{Methods}

\section{Sources}

The meta-analysis was designed following the Meta-analysis of Observational Studies in Epidemiology (MOOSE) Group guidelines. ${ }^{17}$ A systematic review was 
preformed to identify, evaluate, and summarize the literature related to establishing a rate of dysphagia and RLN palsy after reoperative anterior cervical spine surgery. Investigators included residents and attending physicians from the University of Alabama at Birmingham in the departments of otolaryngology and neurosurgery. The MEDLINE, PubMed, and Google Scholar databases were searched using the internet browser Mozilla Firefox version 4.42.0.0. The search terms included "revision anterior cervical spine surgery," "re-operative anterior cervical spine surgery," "dysphagia," and "recurrent laryngeal nerve dysfunction." Full-text articles of all potentially appropriate studies were reviewed, and a hand search of the bibliographies of each retrieved article was conducted to identify publications not found in previous searches. A listing of all included studies is not included here, but is available upon request. The date ranges of search articles spanned from 1988 to the present. Unpublished studies and abstracts were not included in the meta-analysis. No attempts were made to contact the authors of the included studies.

\section{Study Eligibility Criteria}

The inclusion criteria (i.e., all criteria must be present) were as follows: 1) published in the English language; 2) related to reoperative anterior cervical spine surgery; and 3) related to outcome of RLN. The exclusion criteria (i.e., none could be present) were as follows: 1) no specific population, exposure, and outcome (e.g., too broad); 2) nonscientific studies (such as commentaries, letters to the editor, etc.); and 3) literature reviews.

\section{Study Selection}

Two reviewers (M.S.E. and A.S.G.) screened the results independently after a calibration and training process. Disagreements between reviewers were resolved by discussion until a consensus was reached. Level 1 screening consisted of evaluating all available information returned by the electronic search. Level 2 screening consisted of evaluating full-text reports for studies deemed potentially eligible after Level 1 screening. Reviewers were not blinded during the search process. Appropriateness of the studies was determined from the aforementioned inclusion/exclusion criteria. Study types included case series, retrospective chart reviews, retrospective patient questionnaires, and prospective longitudinal follow-up studies.

\section{Statistical Analysis}

Results for this study are reported as a meta-analysis. The outcome of interest was the rate of RLN following reoperative ACDF surgery. Heterogeneity among the individual studies was assessed using 2 separate estimates, the Cochran's Q statistic and the I ${ }^{2}$ statistic. Cochran's Q statistic weighs the contribution of each study by its inverse variance, with a low $p$ value considered an indicator of between-study variability. Because Cochran's Q statistic often has poor power to detect true heterogeneity in a meta-analysis involving a small number of studies, the $\mathrm{I}^{2}$ statistic was also computed as a quantification of the proportion of variation in effect size due to heterogeneity. ${ }^{11}$
Given the diverse nature of study populations included in this meta-analysis, the assumption was made that the differences in effect-size outcomes were not only due to errors in sampling but also due to differences in the study populations. Therefore, the random-effects model was used to calculate the summary estimates of the outcome data. Random-effects weights based on within-study and between-studies variances were used to generate a weighted overall rate estimate of the pooled effect size, along with its accompanying 95\% confidence interval (CI).

Once the statistical analysis for the study was performed, a weighted overall summary rate with its accompanying variance and 95\% CI was calculated and compared with each individual study using a forest plot. The overall summary rate calculated through the randomeffects model was used as a standard, with each individual study demonstrated in relation to it. All studies are reported with their individual 95\% CIs.

Statistical analysis was performed using StatsDirect statistical software (version 3, StatsDirect Ltd. 2013) with all results confirmed by parallel analysis using Comprehensive Meta-Analysis (version 2.2, Biostat). All p values were considered statistically significant at the 0.05 level.

\section{Results}

Our systematic review yielded a total of 345 papers on the initial search. Eight papers fulfilled our inclusion criteria, whereas the other 337 were excluded because they did not address at least 1 of the inclusion criteria. Other potential reasons for exclusion were: 1) studies not in English, 2) those not addressing recurrent ACDF surgery but only initial procedures, and 3) those not identifying postsurgical RLN palsy but rather identifying presurgical rates. Non-English studies were excluded for ease of interpretation. As a result, only 8 studies were identified that met all required eligibility parameters.

\section{Analysis of Studies and Data}

The studies included in this meta-analysis were prospective, longitudinal follow-up studies and retrospective chart reviews. RLN injury was defined as hoarseness or dysphagia, determined primarily by questionnaires obtained at different points in the postoperative period, dysphagia evaluations or indices, and direct evaluation by otolaryngologists for vocal cord paresis. Results were coded according to the determinations of multiple different assessors, whether through subjective assessment of dysphagia and hoarseness from a patient's perspective or from scoring/evaluation by independent evaluators.

Data were classified and coded with the use of multiple raters, although most studies attempted to objectify their results by using standardized grading systems or inspection by an otolaryngologist to determine RLN paresis. In many cases, researchers were not blind to the data collection and results, but this was mostly related to the study methods as retrospective chart reviews or case studies and did little to influence the ultimate findings. In those studies that used a third party to assess RLN injury, the blinding of the assessors was often not addressed (Table 1). 
TABLE 1. Papers included in the meta-analysis with type of study, number of patients, and those with dysphagia and evidence of RLN injury

\begin{tabular}{|c|c|c|c|c|c|c|}
\hline Authors \& Year & Study Type & $\begin{array}{l}\text { Side of } \\
\text { Approach }\end{array}$ & $\begin{array}{l}\text { No. Undergoing } \\
\text { Reoperative } \\
\text { ACDF }\end{array}$ & $\begin{array}{c}\text { No. w/ } \\
\text { Dysphagia }\end{array}$ & Dysphagia \% & How Dysphagia Was Determined \\
\hline Kalb et al., 2012 & $\begin{array}{l}\text { Retrospective chart } \\
\text { review }\end{array}$ & $\begin{array}{l}44.4 \% \mathrm{rt} \\
55.5 \% \text { It }\end{array}$ & 24 & 3 & 10.8 & $\begin{array}{l}\text { Questionnaire, dysphagia dis- } \\
\text { ability index }\end{array}$ \\
\hline Lee et al., 2007 & $\begin{array}{l}\text { Prospective longitudi- } \\
\text { nal FU study, ques- } \\
\text { tionnaire based }\end{array}$ & Not specified & 36 & 10 & $\begin{array}{l}62 \text { at } 1 \mathrm{mo}, 47.4 \text { at } 2 \\
\text { mos, } 29.7 \text { at } 6 \& 12 \\
\text { mos, } 27.7 \text { at } 24 \text { mos }\end{array}$ & Bazaz dysphagia grading system \\
\hline Gok et al., 2008 & $\begin{array}{l}\text { Retrospective chart } \\
\text { review }\end{array}$ & Not specified & 13 & 1 & 6.67 & $\begin{array}{l}\text { Nurick myelopathy scale score, } \\
\text { plain radiographs }\end{array}$ \\
\hline Bazaz et al., 2002 & $\begin{array}{l}\text { Prospective longitudi- } \\
\text { nal FU study }\end{array}$ & $\mathrm{Lt}$ & 32 & 6 & $\begin{array}{l}50 \text { at } 1 \text { mo, } 37.5 \text { at } 2 \\
\text { mos, } 18.8 \text { at } 6 \text { mos }\end{array}$ & Telephone questionnaire \\
\hline $\begin{array}{l}\text { Beutler et al., } \\
2001\end{array}$ & $\begin{array}{l}\text { Retrospective chart } \\
\text { review }\end{array}$ & Rt 173, It 155 & 21 & 2 & 9.50 & $\begin{array}{l}\text { Persistence of hoarseness at 2- } \\
\text { wk FU or documentation of } \\
\text { vocal cord paresis by otolaryn- } \\
\text { gologist }\end{array}$ \\
\hline Coric et al., 1997 & Case series & Unknown & 19 & 2 & 10.50 & Transient hoarseness \\
\hline $\begin{array}{l}\text { Apfelbaum et al., } \\
2000\end{array}$ & $\begin{array}{l}\text { Retrospective chart } \\
\text { review }\end{array}$ & $\mathrm{Rt}$ & 30 & 3 & 10.00 & $\begin{array}{l}\text { Evaluated by otolaryngologist for } \\
\text { vocal cord paralysis }\end{array}$ \\
\hline Chen et al., 2013 & $\begin{array}{l}\text { Prospective longitudi- } \\
\text { nal FU study }\end{array}$ & Not specified & 63 & 5 & 7.90 & $\begin{array}{l}\text { Questionnaire, visual analog } \\
\text { scale, Japanese Orthopaedic } \\
\text { Association scale }\end{array}$ \\
\hline
\end{tabular}

FU $=$ follow-up.

\section{Findings}

A total of 238 patients who underwent reoperative ACDF surgeries were included. Thirty-three RLN palsies were identified, yielding an overall estimated rate, calculated using a random-effects model, of $14.1 \%$ for RLN injury after reoperative ACDF (Table 2). In evaluating these data, many studies analyzed population demographics, such as age and sex. In all cases, it was concluded that all members of the study population had undergone a previous ACDF procedure at some prior point.

The individual study estimates with their 95\% CIs are shown on the forest plot (Fig. 1). Of the studies included in the meta-analysis, it should be noted that whenever rates over time were given, we used the rate of RLN injury at the farthest date from surgery as the inclusion rate for the meta-analysis. For example, although Lee et al. report RLN palsy in 24 of 38 patients treated with revision
ACDF surgery at 1 month postoperatively, this rate fell to 10 of $36(27.7 \%)$ by 24 months postoperatively, and therefore a rate of $27.7 \%$ was recorded in the meta-analysis. ${ }^{14}$ While all studies included in our analysis addressed the topic of RLN injury during revision ACDF, only 2 studies examined this topic as the main outcome objective. In every report cited, patients who received revision ACDF surgery were a subset of the overall ACDF study population. All studies included in this meta-analysis addressed the issue of interest, RLN injury after revision ACDF surgery.

\section{Statistics}

The statistical analysis used to generate the forest plot (Fig. 1) is presented in Table 2. The overall Cochran's Q statistic and $\mathrm{I}^{2}$ statistic were $7.8 . \%(\mathrm{p}=0.35)$ and $10.7 \%$, respectively, and indicated limited to no impact of heterogeneity across included studies. With the absence of hetero-

TABLE 2. Statistical analysis of studies reporting RLN injury following reoperative ACDF

\begin{tabular}{|c|c|c|c|c|c|c|c|}
\hline \multirow[b]{2}{*}{ Authors \& Year } & \multirow[b]{2}{*}{ Events } & \multirow{2}{*}{$\begin{array}{c}\text { No. of } \\
\text { Patients }\end{array}$} & \multirow[b]{2}{*}{ Rate } & \multirow[b]{2}{*}{$95 \% \mathrm{Cl}$} & \multirow[b]{2}{*}{ Variance } & \multicolumn{2}{|c|}{$\%$ Weights } \\
\hline & & & & & & Fixed-Effects Model & Random-Effects Model \\
\hline Kalb et al., 2012 & 3 & 24 & 0.125 & $0.027-0.324$ & 0.041 & 10.124 & 10.562 \\
\hline Lee et al., 2007 & 10 & 36 & 0.277 & $0.142-0.452$ & 0.027 & 15.083 & 15.062 \\
\hline Gok et al., 2008 & 1 & 13 & 0.077 & $0.002-0.360$ & 0.074 & 5.579 & 6.069 \\
\hline Bazaz et al., 2002 & 6 & 32 & 0.188 & $0.072-0.364$ & 0.031 & 13.430 & 13.605 \\
\hline Beutler et al., 2001 & 2 & 21 & 0.095 & $0.012-0.304$ & 0.047 & 8.884 & 9.373 \\
\hline Coric et al., 1997 & 2 & 19 & 0.105 & $0.013-0.331$ & 0.051 & 8.058 & 8.567 \\
\hline Apfelbaum et al., 2000 & 3 & 30 & 0.100 & $0.021-0.265$ & 0.033 & 12.603 & 12.861 \\
\hline Chen et al., 2013 & 5 & 63 & 0.079 & $0.026-0.176$ & 0.016 & 26.240 & 23.902 \\
\hline
\end{tabular}




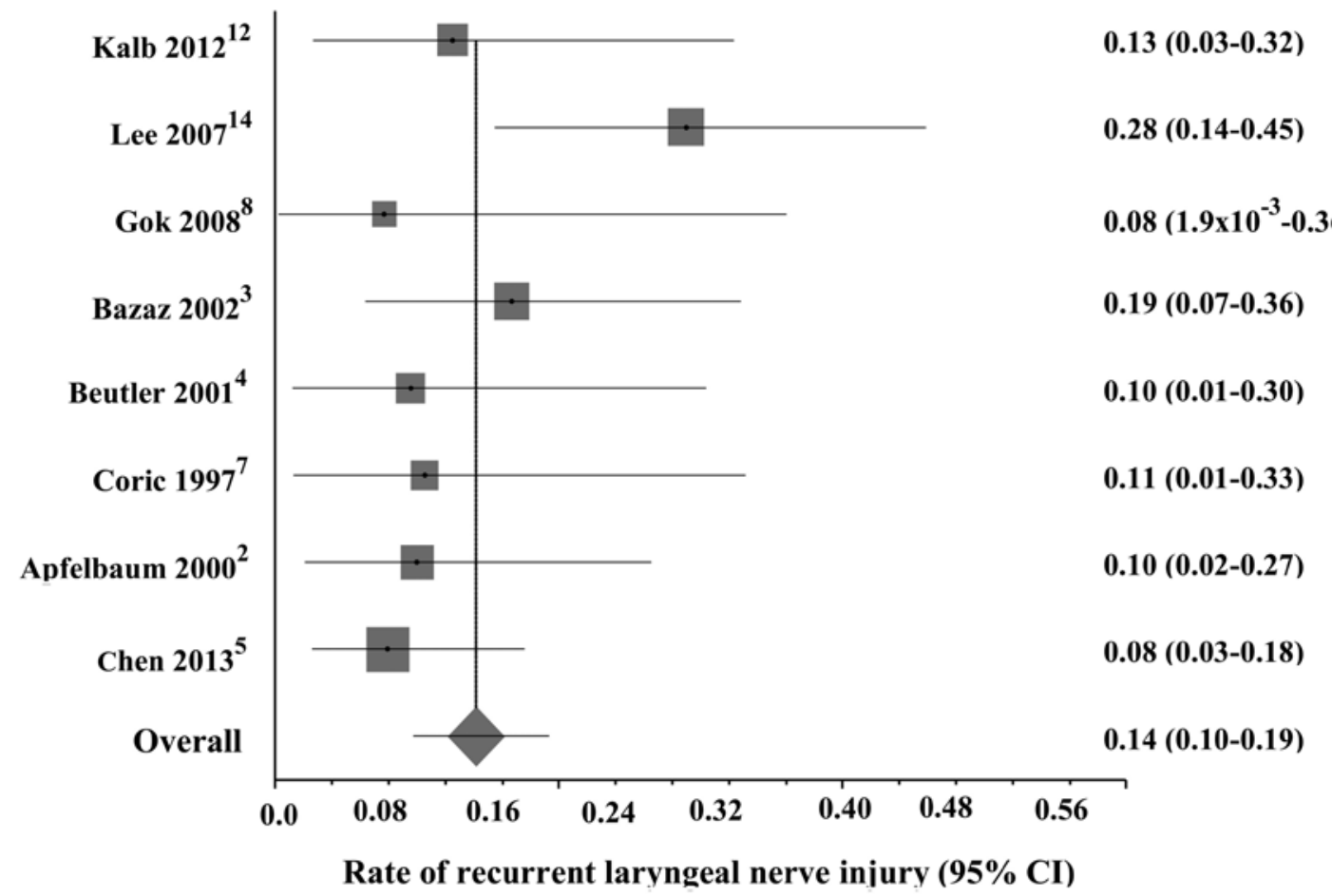

FIG. 1. Forest plot showing the rate of RLN injury $(95 \% \mathrm{Cl})$. Cochran's $Q=7.840$, degrees of freedom $=7, p=0.35 . \mathrm{I}^{2}$ (inconsistency) $=10.7 \%(95 \% \mathrm{Cl} 0.0 \%-60.8 \%)$. Overall summary estimate (fixed-effects model $)=0.140(95 \% \mathrm{Cl} 0.100-0.187)$. Overall summary estimate (random-effects model) $=0.141(95 \% \mathrm{Cl} 0.098-0.191)$.

geneity across studies, fixed-effects models are typically considered appropriate for analyzing studies with negligible variation in study outcomes. However, given the methodological diversity in study designs and the small number of events recorded in these studies, the meta-analysis was performed using both fixed- and random-effects models to compare the summary rate estimates and $95 \%$ CIs using each method. Because overall rate estimates computed using both models gave similar conclusions (14.0\% and $14.1 \%$ for fixed and random effects, respectively), the results from the random-effects model were selected for presentation due to the dissimilarity of the pooled studies. ${ }^{10}$ The $95 \%$ CI for the rate of RLN injury was $9.8 \%-19.1 \%$ according to the fixed-effects model (Fig. 1).

A funnel plot was constructed by graphing standard errors representing variations in sample size on the vertical axis against effect summary size (rates) on the horizontal axis. This graphical analysis was performed to evaluate the potential for publication bias (Fig. 2). Smaller studies are typically concentrated toward the bottom of the plot, because of greater variation and less precision in effectsize estimates. An asymmetrical funnel plot may indicate publication bias due to smaller studies having a greater likelihood of being published if they report large effect sizes and statistical significance. Smaller studies with these attributes will thereby appear disproportionately concentrated on one or the other side of the vertical center line representing the summary estimate. ${ }^{1}$ The funnel plot for this meta-analysis appears to have an unequal distribution on the left side of the plot, suggesting the potential for publication bias.
All 8 studies reported a statistically significant rate of RLN injury following ACDF surgery, with the 3 prospective cohort studies ${ }^{3,5,14}$ contributing the largest sample sizes to the weighted average of the summary rate. As shown in Fig. 1, most of the studies $(n=6)$ reported RLN injury rates less than the $14.1 \%$ overall effect summary, although the $95 \%$ CI for all individual studies overlapped the summary rate estimate.

\section{Discussion}

Our study attempted to summarize the current knowl-

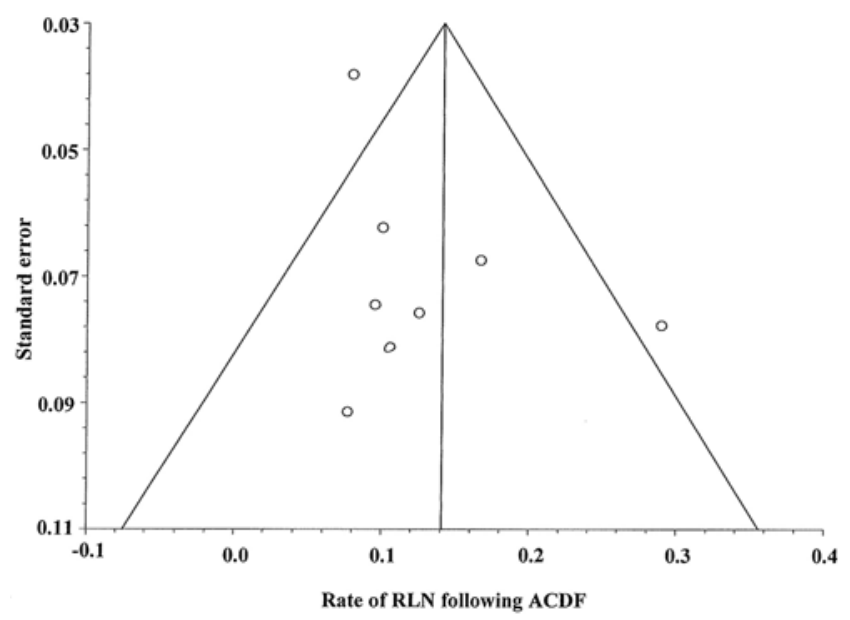

FIG. 2. Funnel plot showing the rate of RLN following ACDF. 
edge of the rate of RLN palsy after revision ACDF surgery. As our literature search suggested, few prior studies have attempted to address this topic. In all cases reviewed in our analysis, the data on RLN injury as a result of revision ACDF surgery were a subset of the overall ACDF populations reported.

An obvious weakness of this meta-analysis, and a weakness of the surgical literature, was the small sample size $(n=238)$. However, to our knowledge, this is the largest sample size to date attempting to address the topic of RLN injury following revision ACDF surgery. Additionally, differences in study designs meant that the method of identifying RLN palsy was not consistent between published series, and therefore in practice. Many authors used subjective dysphagia or hoarseness as the means of identifying injury; fewer investigators used direct evaluation of the vocal cords to identify the rate of paresis. This represents a potential measurement bias. Furthermore, only 3 of the included studies-Bazaz et al., ${ }^{3}$ Lee et al., ${ }^{14}$ and Chen et al. ${ }^{5}$-were prospective longitudinal studies of patients undergoing ACDF surgery., 3 ,14 Prospective longitudinal studies were the preferred study design because they allowed for control of study parameters from the outset and for data analysis in a retrospective fashion. In fact, 6 of the studies included in our review were retrospective studies. Interestingly, as depicted in the forest plot (Fig. 1), the 2 prospective longitudinal studies are found on the right side of the graphic, indicating that they identified a higher incidence of RLN injury after revision surgery. Because these 2 reports represent higher quality studies, their data rightfully affected our overall rate of RLN injury calculation.

Several shortcomings of the literature available for our analysis were noted (Table 3). For example, no mention of preoperative assessment for dysphagia was made in most of the studies included in the analysis. The only exception is the study by Lee et al., ${ }^{14}$ in which the statement was made that patients with preoperative dysphagia had been excluded; however, no indication was given regarding how the swallowing dysfunction was determined. An additional, and potentially important, issue omitted from the literature is whether any surgical assistance was received from an attending otolaryngologist, which could influence the overall RLN injury rate, in any of the series.

It is also still unclear whether the side of approach has an effect on RLN injury; there was not a consistent choice of operative approach side among the studies. In most cases, this was determined based on the surgeon's preference. Coric et al. ${ }^{7}$ performed revision surgeries through the same incision as the primary surgery, although it was not specified whether these were from the right or left side. In contrast, the study by Chen et al. ${ }^{5}$ noted that their revision surgeries were performed through the contralateral side in their 63 patients. For the other 6 studies included, the relationship of the side of revision surgery in relation to the side of primary surgery was not specified. Several previous examinations into this topic have not shown a significant difference in the rate of RLN injury based on approach from the left or the right side of the neck. ${ }^{4}$ Older studies have suggested that the anatomical course differences between the left and right RLN may impact RLN

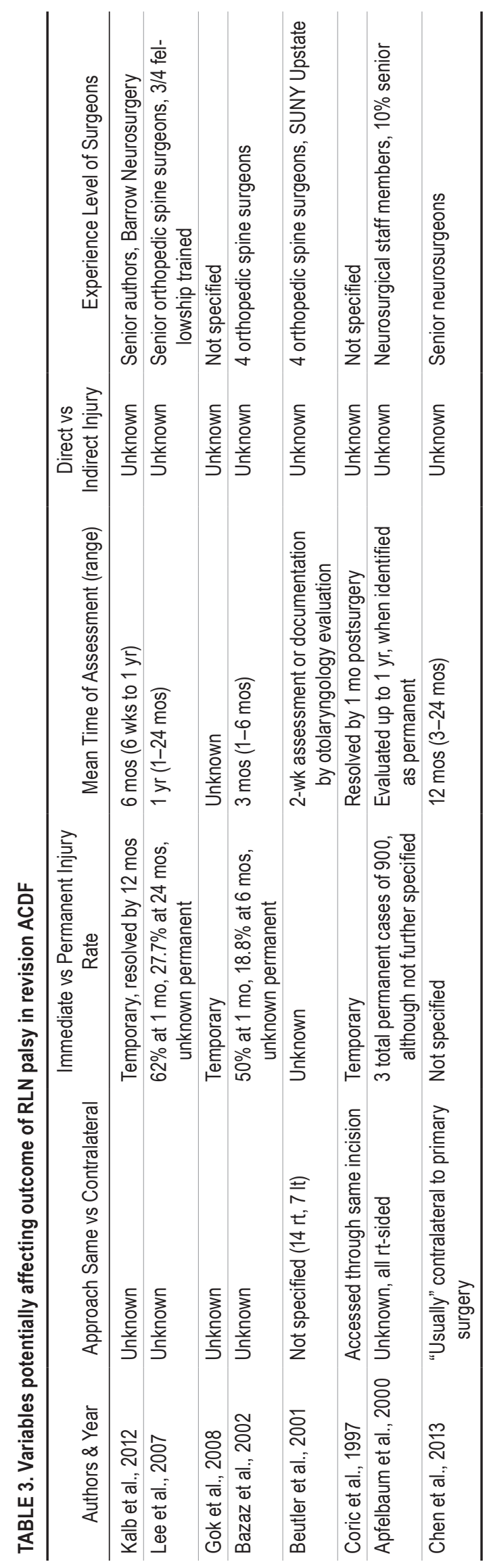


injury rates. This is highlighted in the conflicting reports of Tew and Mayfield compared with that of Heeneman, where rates of RLN injury were higher in left-sided ACDF exposures in the former versus a greater incidence of RLN injury from right-sided exposure in the latter. ${ }^{2,9,18}$

The timing of assessment of RLN injury varied widely in the studies. Kalb et al. ${ }^{12}$ looked at RLN injuries between 6 weeks and 1 year, with a 6-month mean. Lee et al. ${ }^{14}$ reported a mean of 1 year, with a range of 1 month to 24 months. In the Gok et al. study, ${ }^{8}$ the follow-up duration is unknown. In the Bazaz et al. ${ }^{3}$ study, follow-up time ranged from 1 to 6 months, with a mean of 3 months. The study by Beutler et al. ${ }^{4}$ only investigated RLN injury at a single point in time, either by symptoms of dysphagia at 2 weeks after the procedure or by otolaryngology evaluation at that time. Coric et al. ${ }^{7}$ mention an incidence of RLN palsy, but all occurrences were temporary and had resolved by 1 month postoperatively. Apfelbaum et al. ${ }^{2}$ only note that they evaluated swallowing function up to 1 year, and that at this point in time they identified the injury as permanent and had no further evaluations. Lastly, Chen et al. ${ }^{5}$ examined dysphagia between 2 and 24 months, with a mean of 1 year.

Additionally, the level of operation in the cervical spine was not consistent across studies. While it is difficult to define exactly how much this might have affected the results, it is reasonable to assume that certain levels would lend themselves to increasing rates of RLN injury and paresis. Kalb et al. reported in their 2012 study that ACDF at C4-5 and C5-6 levels were most often associated with dysphagia, with rates of $67 \%$ and $81 \%$, respectively. ${ }^{12}$ These rates were significantly higher than rates of RLN palsy after ACDF procedures performed at higher levels of the cervical spine. ${ }^{12}$ A study by Apfelbaum et al. revealed similar findings of increased RLN paresis with dysphagia at lower ACDF levels. The authors proposed that this was secondary to larger endotracheal deflection and a greater potential stretch on the RLN when operating lower in the cervical spine. $^{2}$

Also, the number of levels involved in ACDF surgery can affect the rate of RLN injury. As progressively more levels of the cervical spine are treated with ACDF procedures, the requirement for better visualization, and thus greater retraction, can potentially increase the rate of dysphagia in surgical patients. A study by Bazaz et al..$^{3}$ in 2002 compared the number of levels treated with ACDF and the incidence of dysphagia in the subsequent postoperative months following the procedure. When comparing 1- and 2-level ACDF surgeries, there was a statistically significant difference in RLN paresis rates between the two at 1 month postoperation (higher injury rate with multiple-level surgery), which disappeared by the 2nd month. Three-level ACDF surgeries in their series had a statistically significant $(p=0.02)$ rate of postoperative persistent dysphagia 2 months following surgery. However, they reported that all differences resolved by 6 months postoperatively, regardless of the number of levels treated. ${ }^{3}$

Many of the studies specify that the surgeons were senior members of the faculty at their respective institutions. The Lee et al. ${ }^{14}$ study even goes so far as to specify that 3 of the 4 surgeons were fellowship trained in orthopedic spine surgery. The Apfelbaum et al. study, ${ }^{2}$ meanwhile, states that $10 \%$ of the surgeons were senior faculty members, but does not further delineate the experience levels of the surgeons. Only 2 studies, those by Gok et al. ${ }^{8}$ and Coric et al., do not make any mention of the surgeons' experience. In no paper was the length of surgical time addressed. However, the authors of this meta-analysis recognize that the length of the procedure could be an important variable contributing to the risk of RLN injury with ACDF.

The age of the patient treated with ACDF can also be considered an independent risk factor for RLN injury. Kalb et al. reported that the mean age of patients with dysphagia following ACDF was determined to be 55 years as opposed to 50 years in those without RLN paresis. This finding was statistically significant $(p=0.05) \cdot{ }^{12}$ Bazaz et al. reported a similar finding of increased age in their RLN injury group, 53 years in their patients with postoperative RLN palsies compared with 50 years for those treated with ACDF without RLN palsy; their age differences were not statistically significant. ${ }^{3}$

Lastly, the means of data collection to determine RLN palsy was a potential confounder, as potential palsies were not consistently assessed across patients in the studies. Investigators often used subjective questionnaires to determine the presence of RLN paresis and the amount of disability. Self-reporting of RLN injury by patients has its limitations. This is in contrast to the studies that used direct visualization of the vocal cords to assess function. Other factors, such as bias of the assessors and inconsistency in who performed the evaluations or interpreted the questionnaires, or both, could have skewed these data as well.

Despite its limitations, our analysis was successful in achieving its objective of identifying an estimate of the rate of RLN injury after revision ACDF surgery. In our review, $14.1 \%$ of patients undergoing a repeat ACDF procedure experienced some form of postoperative RLN injury, defined as dysphagia, hoarseness, or proven vocal cord paresis.

While the rate of $14.1 \%$ is significantly higher than the suggested rate of RLN injury after initial ACDF, the majority of the studies included in our meta-analysis had RLN palsy rates that fell beneath our calculated $14.1 \%$, as depicted in Fig. 1. This suggests that the study by Lee et al. in 2007, the largest of the studies reviewed with an RLN injury rate of $29 \%$, may have significantly influenced our analysis. ${ }^{14}$ Because the data from Lee et al. were collected prospectively, it is one of the highest-quality papers included in our review, and therefore its influence in the final results is likely well justified. RLN injury after reoperative ACDF in our meta-analysis ranged from $7.7 \%$ to $28 \%$; however, only 3 of the 8 studies reported rates $>11 \%$.

In reviewing the available literature, publication bias was a potential source of systematic error. While our meta-analysis design was able to identify a significant relationship between revision ACDF surgery and a greater likelihood of RLN injury, the possibility exists that studies reporting no change in RLN injury rates after revision ACDF surgery are less likely to be published.

While the results of our analysis suggest that the rate 
of RLN injury after revision ACDF surgery is higher than that identified in initial ACDF procedures, there are other potential explanations for these findings. First, some of the studies considered in this meta-analysis described rates of RLN palsy after reoperative $\mathrm{ACDF}$ at least equivalent to first-time ACDF procedures. Winslow et al. in 2001 reported that patients undergoing reoperative ACDF did not have higher rates of dysphagia but instead had higher rates of postoperative complaints in general. ${ }^{19}$ We did not include their reports in the meta-analysis due to a paucity of objective and consistent data to analyze. Furthermore, the higher rate of RLN injury in the revision ACDF population may be due to differences in the identification of RLN palsy, greater contemporary awareness of RLN palsy, and the inclusion of both temporary and permanent cases of RLN palsy in the series reported. Lastly, the reported data on RLN palsy after ACDF may be skewed by inconsistent time courses of examination and follow-up. Some studies examined patients up to 2 years postoperatively, ${ }^{5,14}$ while others reported their findings at the 2 -week follow-up. ${ }^{4}$

\section{Conclusions}

Our review identified the risk of RLN palsy after reoperative ACDF surgery to be $14.1 \%$. This rate is typically higher than the rate of RLN injury after initial ACDF, irrespective of the operative approach. In addition, our study has identified several areas of focus for future research, including standardized operation and methodology for evaluation of RLN dysfunction before and after reoperative ACDF surgery, and a prospective study design for quantifying adverse outcomes, including RLN injury, and reliability of the measures assessing these outcomes. Future research should focus on organizing studies with the specific objective of addressing the rate of RLN injury in reoperative ACDF, utilizing preoperative evaluation of the patient's baseline swallowing function, and on determining the specific risk factors related to revision ACDF surgery that make it more susceptible to RLN injury. By understanding the factors that contribute to RLN injury, physicians can take steps to prevent this important potential complication.

\section{References}

1. Anzures-Cabrera J, Higgins JPT: Graphical displays for meta-analysis: An overview with suggestions for practice. Res Synth Methods 1:66-80, 2010

2. Apfelbaum RI, Kriskovich MD, Haller JR: On the incidence, cause, and prevention of recurrent laryngeal nerve palsies during anterior cervical spine surgery. Spine (Phila Pa 1976) 25:2906-2912, 2000

3. Bazaz R, Lee MJ, Yoo JU: Incidence of dysphagia after anterior cervical spine surgery: a prospective study. Spine (Phila Pa 1976) 27:2453-2458, 2002

4. Beutler WJ, Sweeney CA, Connolly PJ: Recurrent laryngeal nerve injury with anterior cervical spine surgery risk with laterality of surgical approach. Spine (Phila Pa 1976) 26:1337-1342, 2001

5. Chen Y, He Z, Yang H, Liu X, Wang X, Chen D: Anterior cervical diskectomy and fusion for adjacent segment disease. Orthopedics 36:e501-e508, 2013

6. Cho SK, Lu Y, Lee DH: Dysphagia following anterior cervi- cal spinal surgery: a systematic review. Bone Joint J 95B:868-873, 2013

7. Coric D, Branch CL Jr, Jenkins JD: Revision of anterior cervical pseudarthrosis with anterior allograft fusion and plating. J Neurosurg 86:969-974, 1997

8. Gok B, Sciubba DM, McLoughlin GS, McGirt M, Ayhan S, Wolinsky JP, et al: Revision surgery for cervical spondylotic myelopathy: surgical results and outcome. Neurosurgery 63:292-298, 2008

9. Heeneman H: Vocal cord paralysis following approaches to the anterior cervical spine. Laryngoscope 83:17-21, 1973

10. Higgins JPT, Thompson SG, Deeks JJ, Altman DG: Measuring inconsistency in meta-analyses. BMJ 327:557-560, 2003

11. Huedo-Medina TB, Sánchez-Meca J, Marín-Martínez F, Botella J: Assessing heterogeneity in meta-analysis: Q statistic or I2 index? Psychol Methods 11:193-206, 2006

12. Kalb S, Reis MT, Cowperthwaite MC, Fox DJ, Lefevre R, Theodore N, et al: Dysphagia after anterior cervical spine surgery: incidence and risk factors. World Neurosurg 77:183-187, 2012

13. Kriskovich MD, Apfelbaum RI, Haller JR: Vocal fold paralysis after anterior cervical spine surgery: incidence, mechanism, and prevention of injury. Laryngoscope 110:14671473,2000

14. Lee MJ, Bazaz R, Furey CG, Yoo J: Risk factors for dysphagia after anterior cervical spine surgery: a two-year prospective cohort study. Spine J 7:141-147, 2007

15. Paniello RC, Martin-Bredahl KJ, Henkener LJ, Riew KD: Preoperative laryngeal nerve screening for revision anterior cervical spine procedures. Ann Otol Rhinol Laryngol 117:594-597, 2008

16. Siska PA, Ponnappan RK, Hohl JB, Lee JY, Kang JD, Donaldson WF III: Dysphagia after anterior cervical spine surgery: a prospective study using the swallowing-quality of life questionnaire and analysis of patient comorbidities. Spine (Phila Pa 1976) 36:1387-1391, 2011

17. Stroup DF, Berlin JA, Morton SC, Olkin I, Williamson GD, Rennie D, et al: Meta-analysis of observational studies in epidemiology: a proposal for reporting. Meta-analysis Of Observational Studies in Epidemiology (MOOSE) group. JAMA 283:2008-2012, 2000

18. Tew JM Jr, Mayfield FH: Complications of surgery of the anterior cervical spine. Clin Neurosurg 23:424-434, 1976

19. Winslow CP, Winslow TJ, Wax MK: Dysphonia and dysphagia following the anterior approach to the cervical spine. Arch Otolaryngol Head Neck Surg 127:51-55, 2001

\section{Disclosures}

The authors report no conflict of interest concerning the materials or methods used in this study or the findings specified in this paper.

\section{Author Contributions}

Conception and design: Erwood, Hadley, Gordon, Carroll, Walters. Acquisition of data: Erwood, Hadley, Gordon, Carroll, Walters. Analysis and interpretation of data: Erwood, Hadley, Gordon, Agee, Walters. Drafting the article: Erwood, Hadley, Gordon, Carroll, Walters. Critically revising the article: Erwood, Hadley, Carroll, Walters. Reviewed submitted version of manuscript: Erwood, Hadley. Approved the final version of the manuscript on behalf of all authors: Erwood. Statistical analysis: Agee.

\section{Correspondence}

Matthew S. Erwood, Department of Neurosurgery, Faculty Office Tower, Ste. 1008, University of Alabama at Birmingham, 1720 2nd Ave. S, Birmingham, AL 35294-3410. email: merwood@ uabmc.edu. 